\title{
Non-Physician Endoscopy: How Far Can We Go?
}

\author{
Ute Gabriele Pfeifer ${ }^{a} \quad$ Dieter Schilling ${ }^{b}$ \\ ${ }^{a}$ Endoskopieabteilung, Evangelisches Krankenhaus Düsseldorf, Düsseldorf, Germany; \\ ${ }^{\mathrm{b}}$ Medizinische Klinik 2, Diakonissenkrankenhaus Mannheim, Germany
}

\section{Keywords}

Non-physician endoscopy · Nurse endoscopist .

Delegation of tasks · Colorectal cancer screening

\section{Summary}

Background: The delegation of medical tasks to trained nurses is still little discussed in Germany. Methods: To get a picture of the current extent of non-physician endoscopy worldwide, we performed a systematic literature research. The following databases were used: CINAHL ${ }^{\circledR}$, Cochrane Library, the German National Library of Medicine (ZB MED), OPAC, DIMDI, PubMed and MEDLINE. The research words were: nurse and practitioners or nurse clinician and diagnosis and organization and administration. Actual journals and references were used to find relevant studies (hand research). Results: Non-physician endoscopy has been well established in some European countries, in the USA and in several other countries in the western world. Conclusion: The implementation of such programs should be based on solid scientific consideration and evaluated within the framework of the 'delegation rights'.

(c) 2016 S. Karger GmbH, Freiburg

\section{Introduction}

Since non-physician endoscopy has been well established in the western world, including several other European countries and the USA, but not in Germany, it seems sensible to discuss the possible introduction of nurse endoscopists also in Germany. Numerous studies and reports, possibly of limited evidence potential, have shown that the technical skills may be suitably acquired and result in high acceptance at equivalent patient comfort.

However, a financial analysis of the National Health Service (NHS) show that no financial gain is obtained since a physician's skills are required after endoscopy with respect to patient management in long-term care. The implementation of such programs should be based on solid scientific consideration and evaluated within the framework of the 'delegation rights'.

\section{Objectives}

In this article we elucidate the present situation in Germany, the data available from the countries using such schemes with regards to quality and cost effectiveness, and finally how realistic the introduction of 'non-physician endoscopy' is in Germany.

Any such discussion needs to include not only statements from the respective professional societies but also the economic aspects in clinics and the legal position in Germany. This article cannot explore all issues in detail but aims to provide a step towards answering the raised question: 'Non-physician endoscopy: How far can we go?

\section{A Historical Perspective on the Nurse Endoscopist}

The first nurse endoscopists practiced at the Majo Clinic in the USA in the late 1970s and early 1980s [1]. The first publication on the careful and safe execution of rectosigmoidoscopies (insertion $30 \mathrm{~cm}$ ) was published in 2000 [1]. Since then the concept of the nurse endoscopist has been introduced successfully in several countries. In particular, endoscopies in preventative screening and after-care colonoscopies and gastroscopies are frequently carried out by such personnel.

Currently, aspiring nurse endoscopists in Scandinavia, the Netherlands and the UK need to have previously obtained suitable academic qualifications and, after gaining some work experience, may then be trained as nurse endoscopists, alongside junior doctors, in specialized training centers. The medical responsibilities lie wholly with the delegating doctor at all times. The duties of the nurse endoscopist are limited to endoscopy, colonoscopy and the

\section{KARGER \\ Fax +497614520714

() 2016 S. Karger GmbH, Freiburg

$2297-4725 / 16 / 0321-0013 \$ 39.50 / 0$
Prof. Dr. Dieter Schilling 


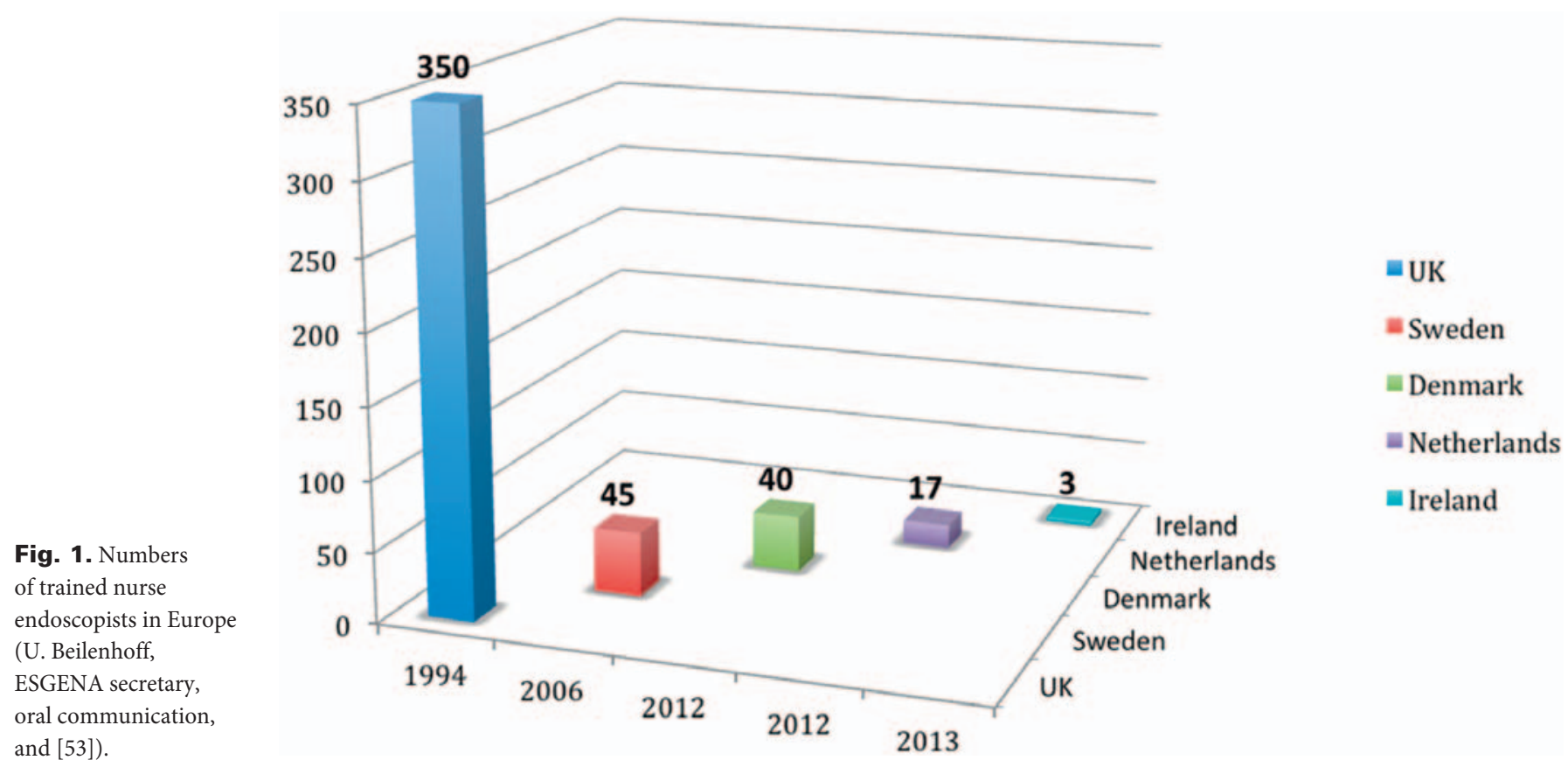

polypectomy of small $(<1 \mathrm{~cm})$ polyps. In Germany, the nurse endoscopist is not yet a recognized profession.

Over the last 38 years, interested and motivated endoscopy personnel have been trained not only in the USA but also in Australia, Canada, China, the UK, Ireland, Sweden, Denmark and the Netherlands. They were trained in universities for gastroscopy and colonoscopy $[2,3]$. The driving forces for this development were a shortage of physicians and a long waiting list for examinations. In particular, in countries in which a national screening program for colorectal colon cancer had been implemented, it was not possible to cover the demands for colonoscopies with doctors alone. Nurse endoscopists now receive high respect from both doctors and patients in the countries listed [4]. More than 450 nurse endoscopists now operate within Europe. At the present time, the exact number of such personnel in the USA is not known (fig. 1). The concept of employing non-physicians in operative procedures is not novel in medicine with nurse anesthetists serving as just 1 example here [5].

\section{Current Scientific Position}

\section{Performance and Adverse Events}

As early as 1987, Weissman et al. [6] reported the successful employment of nurse endoscopists in conducting sigmoidoscopies. DiSario and Sanowski [7], Maule [8] und Schönfeld et al. [9] analyzed the examination results obtained by doctors and nurse endoscopists conducting flexible sigmoidoscopy and found no significant differences. In reviews and studies of endoscopies in the upper and lower gastrointestinal tract [10-15], examination quality and diagnostic precision were also not significantly different.

Equally, in gastroscopy studies by Wildi et al. [16] and Smale et al. [17] no significant differences were recognized in terms of the actual result or anxiety of the patients $(p=0.67)$, entering of the endoscope $(p=0.97)$ or diagnostic quality $(p=0.90)$. A negative feature of the study by Wilde et al. is the use of a pediatric (nurse endoscopist) and standard (gastroenterologist) gastro scope. Meaden et al. [18] compared the diagnostic precision of physician endoscopists and nurse endoscopists in a randomized controlled study. The percentage of careful diagnostic was higher for the nurse endoscopists, $91.6 \%(174 / 190)$, than for the physicians, $53.4 \%$ (93/177) (difference 38.2\%, 95\% confidence interval 30.547.2\%). More recent studies in 2011 and 2014 showed a similar adenoma detection rate in colonoscopy [19-21]. Hui et al. [21] quote a complication rate for nurse endoscopists of $9.3 \%$ and for medical endoscopists of $9.0 \%(\mathrm{p}=0.899)$ in their study. Koornstra et al. [19] found complication rates for nurse endoscopists of $0.33 \%$, for medical endoscopists of $0.67 \%$ and for specialists of $0 \%$. Unfortunately, most studies do not exhibit a high level of evidence. Of about 30,000 non-physician procedures, only 1,400 were conducted in a controlled manner and none of the studies were performed using a blind research design. Most reports simply provide confirmation that the training programs work.

It is far harder to provide objective measurements or analyses to judge whether nurse endoscopists possess comparable cognitive skills, i.e. that they are capable of interpreting the endoscopy results in connection with the clinical setting as proficiently, or indeed whether they have comparable knowledge of alternative procedures at the existing endoscopic facilities. These skills are paramount for the epicritic summary of the examination and the instructions for subsequent procedures. For the concept of the nurse endoscopist this analysis might not be necessary, although it is clear that this aspect of possible involvement of a physician follow- 
ing the endoscopy has to be taken into account when economic analysis is carried out [22].

\section{Patient Satisfaction and Acceptance}

No differences in patient satisfaction were registered in the area of gastroscopy $[15,16]$. The studies von Koornstra et al. [19], Limoges-Gonzales et al. [20] und Hui et al. [21] report a particularly high patient satisfaction when nurse staff and physicians are directly compared. The vast majority of patients, $99.3 \%, 98 \%$ and 98.9\% respectively for these studies, stated that they would be happy to have further colonoscopies with nurse staff [19-21] (table 1). In a further examination, $95 \%$ of 734 patients questioned were satisfied with the examination, $72 \%$ of patients had no preference for either physician or nurse examiner [23] (fig. 2 and 3).

\section{Cost Effectiveness}

Gertler et al. [24] und Spiegel [25] were the first to emphasize the cost effectiveness when trained nurse endoscopists conduct flexible sigmoidoscopies. However, there are only few detailed cost effectiveness analyses. Studies by Massl et al. [12] report a cost reduction of EUR 7.61, when 1 gastroenterologist supervises 3 nurse endoscopists. However, the cost of follow-ups, histology and involvement of consultants are not included in these calculations. These issues were investigated in an analysis by the British $\mathrm{Na}$ tional Health Service (NHS) [26]. According to this study, physician costs (GBP 1.82/min) outweigh those of nurses (GBP 0.53/ min) significantly, but nurses' patients had a substantially higher need for subsequent endoscopies within the first year. As a result, when cognitive costs are included in the calculations, the cost of the physicians is lower. The authors of this trial calculated that with $87 \%$ probability a physician is more cost effective than a nurse. Riphaus et al. [27] studied the results of video capsule endoscopies and found a cost reduction from EUR 17.82 to EUR 13.23 when trained endoscopic nursing staff conducted the interpretation of the obtained results. In a study by Bossa et al. [28], the cost reduction in the same scenario was quoted as $30 \%$. The largest cost reduction (USD 324.00) in the interpretation of video capsule results was reported by Niv and Niv [29], a finding not directly relevant for the German setting.

\section{The Nurse Endoscopist - an International Perspective}

The American Society for Gastrointestinal Endoscopy (ASGE) endorses the use of nurse endoscopists in conducting flexible sigmoidoscopies and in the initial interpretation of video capsule endoscopy as long as the correct training and supervision structures are in place (Level 1B, strong recommendation). For any decision on gastroscopy und colonoscopy, the ASGE awaits further clarifying studies [30]. The Society of Gastroenterology Nurses and Associates, Inc. (SGNA), the Gastroenterological Nurses College of Australia (GENCA), the European Society of Gastroenterology and Endoscopy Nurses and Associates (ESGENA), and the British Society of Gastroenterology (BSG) hold similar positions [31-34].

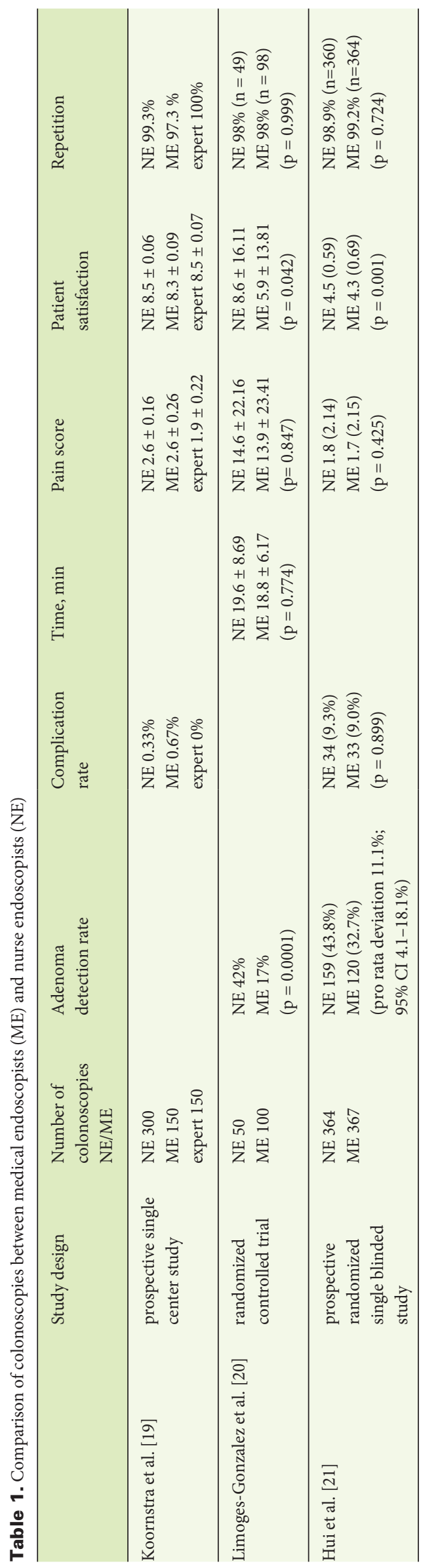


Fig. 2. Results of a survey of physicians' attitude towards nurse endoscopists (1) [23].

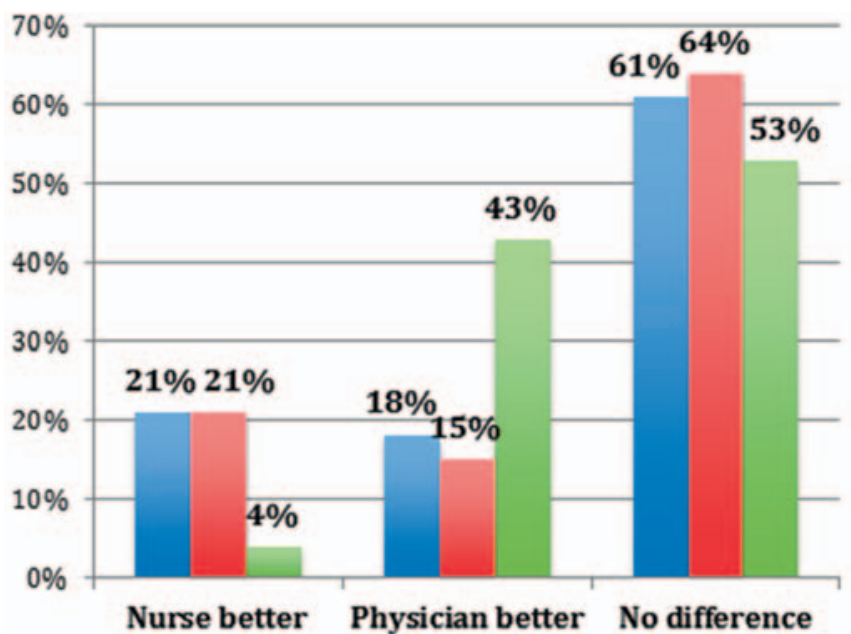

Nurse better Physician better No difference

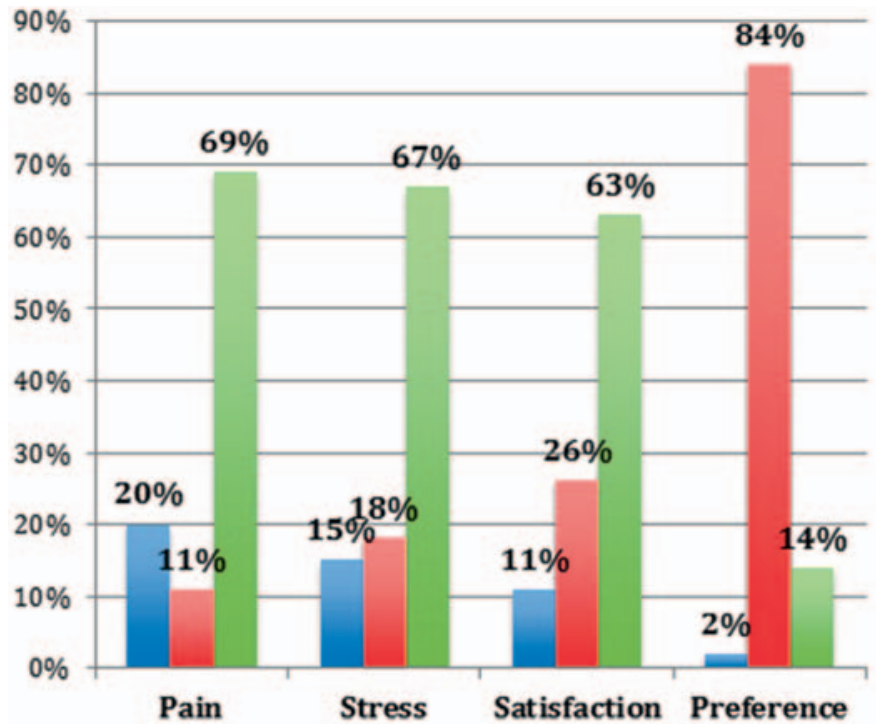

\section{Pain Stress Satisfaction Preference}

= Detection rate

= Complication rate

$=$ No difference
Fig. 3. Results of a survey of physicians' attitude towards nurse endoscopists (2) [23].

\section{= Nurse better \\ = Physician better}

No difference
In Asia, no consensus on the position of nurse endoscopists has been reached [35]. In contrast, the Ministry of Health New Zeeland recognizes added value in the involvement of trained nurse endoscopists and started an education and training program in September 2014 [36].

\section{Motivation for Introduction in Germany}

Any discussion on an introduction of non-physician endoscopy has to be proceeded by detailed facts and figures regarding the capacity for endoscopic examinations and the availability of the physicians and nurses in the health care system.

\section{Capacity of Endoscopic Examinations}

Over the last year, the number of interventional endoscopies has risen, although the number of ambulant colonoscopies have remained unchanged. However, an increase in the latter might also be expected $[37,38]$.

\section{Numbers of Physicians and Nursing Staff}

The demand for medical and nursing treatments is going to rise as demographics continue to change. The working conditions for doctors have improved in the past few years, but have not been able to compensate for a growing desire for a better work-life balance that has developed simultaneously [39]. Moreover, the number of female doctors has risen from $33.6 \%$ to $45.0 \%$ between 1991 and 2013. Young doctors are now more likely again to work in hospital settings with corresponding numbers quoted as $50.7 \%$ (2013) and 51\% (2014) [40]. Furthermore, the German Medical Association (Bundesärztekammer, BÄK) reports that $23 \%$ of practicing doctors will give up their outpatient offices by 2020 [40]. It is also known that every year doctors emigrate abroad; in 2013 alone 2,364 physicians left Germany. Most of these emigrants choose to continue their medical career in Switzerland, Austria or the USA [40]. On their website, the BÄK predicts a deficit of 111,000 doctors by 2030 [40] (fig. 4).

Given this current position and the prediction of continued demographic changes following the aging of the Baby Boomer gen- 
Fig. 4. Movement of German physicians in 2014; updated April 13, 2015 [54].

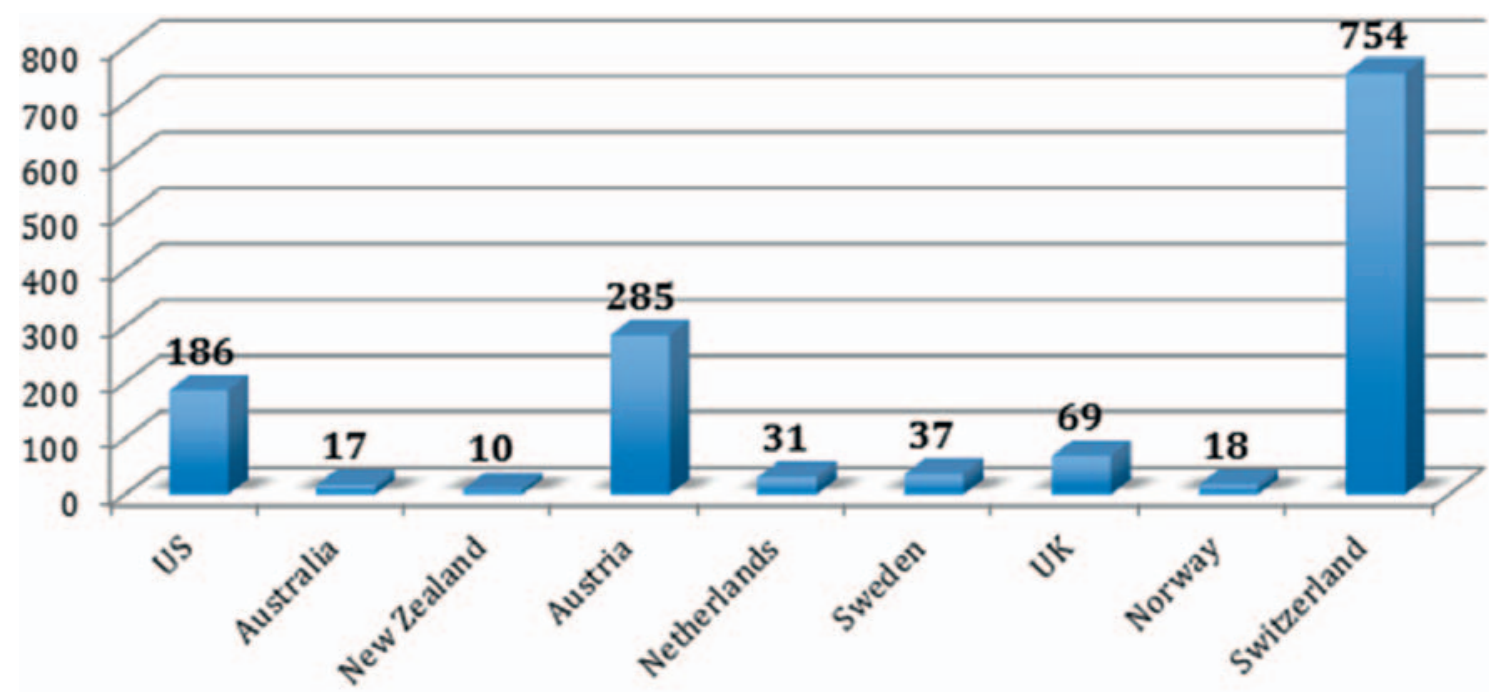

eration, which according to the Bertelsmann Foundation will lead to shortage of 500,000 nursing staff by 2030, any extension of the responsibilities of nursing staff will be a crucial ingredient for their motivation to take up this profession [41].

At the same time, the introduction of nurse endoscopists does not need to lead to a reduction of the physician's responsibilities. The gastroenterologist may then devote his/her attention to clinical endoscopy and the more complex interventions such as endoscopic submucosa dissection, complex polyp resections and endosonographically controlled interventions.

\section{Relevance to Colon Cancer Prevention}

By 2025 the number of people most likely to develop colon cancer will have risen further (for the 65- to 69-year age group from 4.6 million in 2016 to 5.6 million in 2025 ; for the 70 - to 74 -year age group from 3.7 million in 2016 to 4.7 million in 2025) [42]. In 2011 the incidence of colon disease (C28-C21) was at 62,974 (men 34,278 and women 28,696); the annually reported death rate of colorectal cancer is 26,302 [43].

Stimulated by the Stiftung Lebensblicke, on February 1, 2013 the Deutsche Bundestag (German Parliament) passed a law concerning the early detection and registration of colon cancer (Krebsfrüherkennungs- und Registergesetz; KFRG) [44]. The KFRG plans that for individuals in higher risk categories the age limit could be loosened. Detailed definition and drafting of the law lie with the Joint Federal Committee (Gemeinsamer Bundesausschuss; G-BA).

The Central Institute of the Statutory Health Insurance Scheme (Zentralinstitut für kassenärztliche Versorgung) in Germany reports that, between 2003 and 2010, 4.2 million of the entitled 20 million patients took up the offer of a colonoscopy [45], i.e. $21 \%$ of all people over 55 years of age who are entitled to a colonoscopy within the framework of colon cancer prevention.

The G-BA and the central association of the statutory medical insurers (Gesetzliche Krankenversicherung; GKV) are the bodies responsible for the structural implementation of the KFRG. If the planned systematic invitation program is rolled out and accepted, it might well lead to an increase in uptake of $5 \%$ over the next few years.

This corresponds to an additional 1 million preventative colonoscopies. It is therefore important to ask if such a wave of preventative colonoscopies can be absorbed, in addition to the follow-up colonoscopies, by the presently active gastroenterologists in the clinics and surgeries. This forecasted scenario presents a true challenge for all medical staff involved in the existing system even when colon cancer prevention and treatment are considered in isolation. Similar problems were faced in the UK and Denmark and resulted in the introduction of trained endoscopy care staff and their involvement in screening programs.

\section{Non-Physician Endoscopy in Germany}

Considering the financial and staffing issues faced by hospitals and clinics, it is possible that significant waiting times for endoscopic examinations might also become a reality in Germany. Might the training of experienced endoscopy care staff provide a sensible alternative?

Diagnosis/differential diagnosis and recommendation of therapy are primary duties of the physician. Further, it is correctly emphasized that medical intervention should be provided to specialist's standards and that the patient has the right to be treated by a specialist physician [46].

Non-physician endoscopy remains a topic with many unanswered questions in Germany. The first issue is that of the legal position. Are trained nurses permitted to carry out endoscopies? Who is liable when an injury occurs or when the results are wrongly interpreted/communicated? To clarify the legal position, it is crucial to provide a clear formulation of the (general) delegation procedures. According to this, the responsible physician has instruction responsibility and has to direct the duty to be delegated to adequately trained staff who, in turn, take on full responsibility for the professional and appropriate execution of the procedure. As 


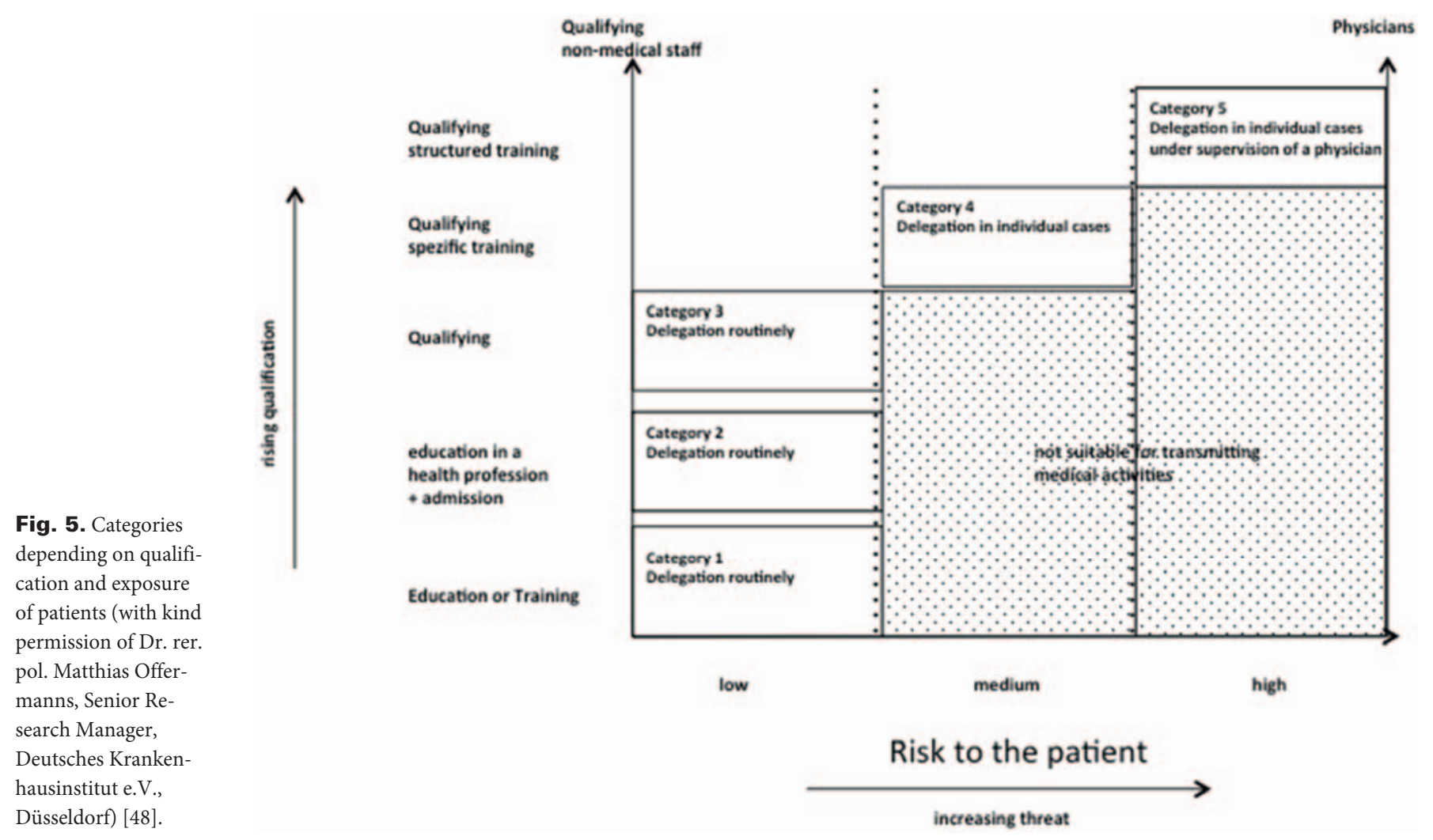

a result the physician needs to order the procedure but the care staff have remonstration rights (and permission), i.e. when they feel inadequately trained or incapable of conducting the procedure. Any care staff who carry out the procedure without adequate training or education commit an act of contributory negligence [47]. In general, the riskier a procedure for a patient, the lower the chances are that any procedures can be delegated to care staff (fig. 5) [48].

Does approbation alone qualify for the execution of (screening) colonoscopy or gastroscopy? The approbation licenses a physician to practice medicine in general. For junior doctors, approbation indicates the start of life-long learning - specialization. Assuming specialized, trained and experienced endoscopy nurses would become involved in a delegation scheme within the framework of the national colon cancer screening program in Germany, questions may arise as to the fee/salaries for colonoscopies. As the cognitive skills of the physician regarding the interpretation and instructions for any subsequent treatment or medical procedure are still required, there will be no changes in salary as a consequence of the clinical reorganization. The concept of the 'nurse endoscopist' is in any circumstances only sustainable if the diagnostic standards (involving those of a specialist) are maintained.

Financial savings are more likely to arise from staffing costs. The (specialist) physician, rather than being limited in his/her expertise to endoscopy, is a physician educated, trained and experienced in practicing general (and specialized) medicine in contrast to the nurse endoscopist, whose expertise is limited to preventative and follow-up endoscopy procedures. International studies pro- vide evidence for the feasibility of such programs, and the ideas elucidated here are based on European models.

The care training in Germany is by no means at all substandard but does, in contrast to international systems, lack the same sort of academization and, therefore, the motivation of caring staff to take on increased responsibility (as embedded in the 2004 Nursing Act (Krankenpflegegesetz; KrPflG) \$3(2 and 3)) [49].

From the arguments above on structural and financial implications, the concept of the 'nurse endoscopist' within the delegation framework discussed seems to be a sensible one. Without question, there is still a sufficient number of gastroenterologists conducting endoscopies in the most populated urban regions of the country. However, it is pertinent to ask if indeed primary diagnostic endoscopies are the final aim of a specialist's tasks/activities/routine. Interventional methodology is developing at breath-taking pace, especially in endoscopy, and due to the demographic changes, complex therapeutic methods have to be handed to junior doctors. Why can a nurse endoscopist not form part of the clinical team? Why should selected nurses not learn practical endoscopic skills and, within defined limits, medical diagnostics? The young medic can develop into a true expert in the field of gastroenterology, while the nurse endoscopist would practice endoscopy entirely for diagnostics and removal of polyps not exceeding $\leq 1 \mathrm{~cm}$. The diagnostics or removal of polyps not exceeding $\leq 1 \mathrm{~cm}$ cannot be the ultimate capability of a gastroenterologist!

However, many physicians still seem to be hesitant with regard to a broader distribution of responsibilities/tasks and consequently 
a delegated authority. Theoretically, from the point of view of the physician, the delegation of such tasks might result in a dent in their knowledge and authority monopole [50].

For the practicing gastroenterologists in Germany there is the danger that the colonoscopy procedure might be less well remunerated if it is not conducted by medical doctors. This argument, which might possibly be brought forward by the KV, i.e. the physicians' self administration, maybe be dispelled with reference to the findings in Great Britain where it was observed that such a system is, in the end, not cheaper. The physician's responsibility and service are to the management of the patient, which is untouched by the role of the nurse endoscopist. In fact, the introduction of nurse endoscopists might provide the possibility for practicing gastroenterologist to offer a broader therapeutic spectrum (including oncology) in their own ambulance.

The employment of nurse endoscopists within the framework of a national colon cancer screening program might for instance be tested with targeted model projects. In 2008, the German government agreed to the establishment of model projects according to $\$ 63(3 \mathrm{c}$ ) of book 5 of the social security statute book (Sozialgesetzbuch V; SGB V), which makes it possible, for the first time, to delegate appropriate activities to care personnel, allowing an independent practicing of medicine (Heilkunde), and includes personnel in the care of the elderly, medical care transfer policy (Heilkundeübertragungsrichtlinie) of the G-BA [51].
In a resolution of the BÄK (February 23, 2012), it is stated that an increased involvement of well-trained and experienced nonphysician medical staff within such delegation models is a sensible alternative allowing good medical care in clinics, hospitals and care homes, especially given the expected demographic changes, the rising medical treatment requirements and the shortage of young doctors entering the medical profession [52].

At present, endoscopic investigations, gastrointestinal function measurements or the analysis of video capsule endoscopy are not a focus of those model initiatives. Yet, it is important to discuss this question, especially given the financial implications outlined above. A first step in exploring this possibility could focus on diagnostic colonoscopy (or gastroscopy) of specialist-based standards to provide a clinical comparative study between doctors and care personnel working under supervision of a gastroenterologist. Successful European training programs could serve as starting models. Research objectives should concentrate on clinical outcomes, patient satisfaction/comfort and financial aspects.

\section{Disclosure Statement}

The authors declare no competing interests.

\section{References}

1 Wright KB: A description of the gastroenterology nurse endoscopist role in the United States. Gastroenterol Nurs 2000;23:2:78-82.

2 Beilenhoff U: Qualifikationsmöglichkeiten für Pflege in der Endoskopie im europäischen Vergleich. EndoPraxis 2011;27:158-165.

3 Pfeifer U: Literaturübersicht zum klinischen Leistungsvergleich zwischen Pflegepersonen und Ärzten in der Gastroenterologie - Teil I. Endo-Praxis 2014;30: 150-155.

4 Pfeifer U: Literaturübersicht zum klinischen Leistungsvergleich zwischen Pflegepersonen und Ärzten in der Gastroenterologie - Teil II. Endo-Praxis 2015;31: 13-19.

5 Matsusaki T, Sakai T: The role of Certified Registered, Nurse Anesthesists in the United States. J Anesth 2011; 25:734-740.

6 Weissman G, Winawer SJ, Baldwin MP, et al.: Multicenter evaluation of training of non-endoscopists in $30-\mathrm{cm}$. Flexible sigmoidoscopy. CA Cancer J Clin 1987;37:26-30.

7 Di Sarrio JA, Sanowski RA: Sigmoidoscopy training for nurses and resident physicians. Gastrointest Endosc 1993;39:29-32.

$\checkmark$ Maule WF: Screening for colorectal cancer by nurse endoscopists. N Engl J Med 1994;330:183-187.

9 Schoenfeld PS, Cash B, Kita J, et al: Effectiveness and patient satisfaction with screening flexible sigmoidoscopy performed by registered nurses. Gastrointest Endosc 1999;49:158-162.

10 Verschuur EM, Kuipers EJ, Siersema PD: Nurses working in GI and endoscopic practice: a review. Gastrointest Endosc 2007;65:469-479.
11 van Putten PG, Ter Borg F, Adang RP, et al.: Colonoscopy performed by nurse endoscopists. Endoscopy 2012;44:1127-1132.

12 Massl R, van Putten PG, Steyerberg EW, et al: Comparing quality, safety, and costs of colonoscopy performed by nurse vs physician trainees. Clin Gastroenterol Hepatol 2014;12:470-477.

13 Pathmakanthan S, Murray I, Smith K, et al: Nurse endoscopists in United Kingdom health care: a survey of prevalence, skills and attitudes. J Adv Nurs 2001;36: 705-710.

14 Day LW, Siao D, Inadomi JM, Somsouk M: Non-phy sician performance of lower and upper endoscopy. Endoscopy 2014;46:401-410.

15 Williams J, Russell I, Durai D, et al: Effectiveness of nurse delivered endoscopy: Findings from randomized multi-institution nurse endoscopy trial (MINuET). BMJ 2009;338:b231.

16 Wildi SM, Wallace MB, Glenn TF, et al: Accuracy of esophagoscopy performed by a non-physician endoscopist with a 4-mm diameter battery-powered endoscope. Gastrointest Endosc 2003;57:305-310.

17 Smale S, Bjarnason I, Forgacs I, et al: Upper gastroentestinal endoscopy performed by nurses: scope for the future? Gut 2003;52:1090-1094.

18 Meaden C, Joshi M, Hollis S, et al: A randomized controlled trial comparing the accuracy of general diagnostic upper gastrointestinal endoscopy performed by nurse or medical endoscopists. Endoscopy 2006;38: $553-560$.

19 Koornstra JJ, Corporaal S, Giezen-Beintema WM, et al: Colonoscopy training for nurse endoscopists: A feasibility study. Gastrointest Endosc 2009;69:688-695.
20 Limoges-Gonzales M, Mann NS, Al-Juburi A, et al: Comparisons of screening colonoscopy performed by a nurse practitioner and gastroenterologists. Gastroenterol Nurs 2011;34:210-216.

21 Hui AJ, Lau JY, Lam PPY, et al: Comparison of colonoscopic performance between medical and nurse endoscopists: a non-inferiority randomised controlled study in Asia. Gut 2014;64:1058-1062.

22 Stephens M, Hourigan LF, Appleyard M, et al: Non physican endoscopist: a systematic review. World J Gastroenterol 2015;28:5056-5071.

23 van Putten PG, van Leerdam ME, Kuipers EJ: The views of gastroenterologists about the role of nurse endoscopists, especially in colorectal cancer screening. Aliment Pharmacol Ther 2009;29:892-897.

24 Gertler S, Murray J, Akashi K, et al: Flexible sigmoidoscopy performed by nurse endoscopists. American Society of Gastrointestinal Endoscopy Abstract 125. Gastrointest Endosc 1991;37:263.

25 Spiegel T: Flexible sigmoidoscopy training for nurses. Gastroenterol Nurs 1995;18:206-209.

26 Richardson G, Bloor K, Wiliams J, et al: Cost effectiveness of nurse delivered endoscopy: Findings from randomised multi institutional nurse endoscopy trial. BMJ 2009;338:b270.

27 Riphaus A, Richter S, Vonderach M, et al: Capsule endoscopy interpretation by an endoscopy nurse - a comparative trial. Z Gastroenterol 2009;47:273-276.

28 Bossa F, Cocomazzi G, Valvano MR, et al: Detection of abnormal lesions recorded by capsule endoscopy - a prospective study comparing endoscopist's and nurse's accuracy. Dig Liver Dis 2006;38:599-602. 
29 Niv Y, Niv G: Capsule endoscopy examination - preliminary review by a nurse. Dig Dis Sci 2005;50:21212124.

30 American Society for Gastrointestinal Endoscopy, Ikenberry SO, Anderson MA, et al: Endoscopy by nonphysicians. Gastrointest Endosc 2009;69:767-770.

31 www.SGNA.org (last accessed July 19, 2015).

32 www.genca.org (last accessed July 19, 2015).

33 www.esgena.org/assets/downloads/pdfs/general/esgena statement_endo_nurses.pdf (last accessed July 19, 2015).

34 www.bsg.org.uk (last accessed July 19, 2015).

35 Sung JJY, Ng SC, Chan FK, et al: An updated Asia Pacific Consensus Recommendations on colorectal cancer screening. Gut 2015;64:121-132.

36 www.health.govt.nz/our-work/health-workforce/newroles-and-initiatives/current-projects/nurses-performing-endoscopies (accessed 19.07.2015).

37 www.destatis.de/DE/ZahlenFakten/GesellschaftStaat/ Gesundheit/Gesundheit.html (last accessed January 11, 2016).

38 Manager BNG, oral communication, January 26, 2015. www.bng.de.

39 www.bundesaerztekammer.de/ueber-uns/aerztestatistik/aerztestatistik-2014/ (last accessed July 19, 2015).
40 www.bundesaerztekammer.de/ueber-uns/aerztestatistik/aerztestatistik-2014/im-krankenhaus-taetige-aerzte/ (last accessed July 18, 2015).

41 www.bertelsmann-stiftung.de/de/unsere-projekte/ pflege-vor-ort/projektthemen/pflegereport-2030/ (last accessed July 18, 2015).

42 www.destatis.de/bevoelkerungspyramide/ (last accessed January 11, 2016).

43 www.lebensblicke.de/darmkrebs/fakten/ (last accessed July 12, 2015).

44 www.bmg.bund.de/fileadmin/dateien/Downloads/Gesetze_und_Verordnungen/Laufende_Verfahren/K/ Krebsregister/Entwurf_eines_Gesetzes_zur_Weiterentwicklung_der_Krebsfrueherkennung_und_zur_Qualitaetssicherung_durch_klinische_Krebsregister.pdf (last accessed January 11, 2016)

45 www.kbv.de/html/298_405.php (last accessed July 18, 2015)

46 http://conventions.coe.int/Treaty/en/Treaties/ Html/164.htm (last accessed July 19, 2015).

47 Großkopf V, Klein H: Krankenpflege und Recht. Balingen, Spitta Verlag, 2002, p 193.
48 Offermanns M, Bergmann KO: Neuordnung von Aufgaben des Ärztlichen Dienstes - Bericht des Deutschen Krankenhausinstituts (DKI), 2008:66-69.

49 www.gesetze-im-internet.de/bundesrecht/krpflg_2004/ gesamt.pdf (last accessed July 20, 2015).

50 Pfeifer U: RCT zur Prüfung der Auswertungsqualität der PillCam Colon Kapselendoskopie von Ärzten und Pflegepersonen im Vergleich zur Expertenauswertung unter Einbezug der beruflichen Identität von Pflegepersonen in der Endoskopie. 2013. http://kidoks.bsz-bw. de/frontdoor/index/index/docId/60 (last accessed January 11,2016).

51 www.g-ba.de/downloads/62-492-600/2011-10-20_RL63Abs3c.pdf (last accessed July 12, 2015)

52 www.bundesaerztekammer.de/fileadmin/user_upload/ downloads/24022012_-_Resolution_Verbaendegespraech.pdf (last accessed July 18, 2015).

53 Tillgaard HR, Dueholm S: Ausbildung zur Nurse Endoscopist - ein Erfolgsbeispiel aus Dänemark. EndoPraxis 2014;30:156-160.

54 www.gbe-bund.de (last accessed January 11, 2016) 